\title{
ARTICLE \\ Climatic Changes and Their Effect on Wildlife of District Dir Lower, Khyber Pakhtunkhwa, Pakistan
}

\section{Asad Ullah ${ }^{1}$ Sayyed Iftekhar Ahmad $^{1}$ Rafi Ullah $^{2}$ Atta Ullah Khan $^{3}$ Sikandar Khan ${ }^{4}$ Waheed Ullah $^{5}$ Abdul Waris $^{6 *}$}

1. Department of Environmental Sciences, Government Degree College Gulabad Chakdara, Dir Lower, Pakistan

2. Plant Ecology and Dendroecology Labartory, Department of Botany, University of Malakand, Pakistan

3. Department of Biotechnology, University of Malakand Chakdara, Dir Lower, Pakistan

4. Pakistan forest Institute, University of Peshawar, Pakistan

5. Department of Environmental Science, COMSATS University Islamabad, Abbotabad Campus, Pakistan

6. Department of Biotechnology, Quaid-i-Azam University Islamabad, Pakistan

\begin{tabular}{l} 
ARTICLE INFO \\
\hline Article history \\
Received: 12 August 2020 \\
Accepted: 11 September 2020 \\
Published Online: 30 September 2020 \\
\hline
\end{tabular}

\section{Keywords:}

Climate change

Wildlife

Temperature

Rainfall

Lower Dir

Pakistan

\begin{abstract}
Climatic changes and their impact are increasingly evident in Pakistan, especially in the mountainous regions. Mountain ecosystems are considered to be sensitive indicators of global warming; even slight variations in temperature can lead to significant shifts in local climate, which can, in turn, drastically affect the natural environment, subsequently altering people's lifestyle and wildlife habitats. The targeted area for the present research was Lower Dir District, Pakistan. The study gathered the required information from primary and secondary sources. Secondary data on temperature and precipitation were obtained from various sources, i.e., local $\mathrm{CBO}$, including WWF Pakistan. Based on information gathered on climate change and wildlife, a detailed questionnaire was designed. Results showed that no regular pattern of the increase was found in temperature from 2010 to 2018; the same was noticed in the rainfall decrease pattern. Results also showed that the leading causes behind climatic changes are an increase in greenhouse gases due to pollution by industries, vehicles, crushing plants, deforestation, and some natural phenomena such as floods. The study showed that more than $80 \%$ of the respondents agreed that climatic effects have a significant impact on wildlife, i.e., the existence of wildlife falls in danger due to climatic changes as it may lead to habitat change, making it difficult for the survival and adaptation of the wildlife. Hence, in consequence, it leads to migration, low growth rate, an increase in morbidity and mortality rate, and finally leading to the extinction of the species or population. It is concluded from the study that people are severely noticing the climatic change and its leading causes are greenhouse gases and deforestation. To control climatic changes and wildlife extinction, we need an appropriate policy for forest conservation, wildlife conservation, prevent hunting, industrial pollution control, vehicle pollution control, increase in plantation, awareness of policy for the control of climatic changes, etc.
\end{abstract}

*Corresponding Author:

Abdul Waris,

Department of Biotechnology, Quaid-i-Azam University Islamabad, Pakistan;

Email:awaris@bs.qau.edu.pk 


\section{Introduction}

$\longrightarrow$ limate is a long-term weather pattern that describes a region ${ }^{[1,2]}$. Climate change is a universal threat to many sectors, such as food production, water and energy, agriculture, human health, economy, and biodiversity ${ }^{[3]}$. Climate changes and its impacts are increasingly evident in Pakistan, especially in the mountainous regions. Mountain ecosystems are considered the sensitive indicators of global warming; even a slight increase or decrease in temperature can cause significant shifts in the local climate, which can, in turn, drastically affect the natural environment and subsequently, humans and wildlife ${ }^{[4]}$. There are many causes of climate change like greenhouses gases, deforestation, industrialization, urbanization, etc. which may lead to global warming, glaciers melting, disasters, floods, migration of birds and wild animals, wildlife and other species extinction ${ }^{[5]}$. Climate changes could occur naturally as a result of the change in the sun's energy or Earth's orbital cycle (natural climate forcing), or it could occur as a result of persistent anthropogenic forcing; such as the addition of greenhouse gases, sulfate aerosols, black carbon to the atmosphere and through land-use change ${ }^{[6,20]}$. The Earth's global surface temperature has risen by approximately 0.8 ${ }^{\circ} \mathrm{C}$ while in the $70 \mathrm{~s}$ by $0.5^{\circ} \mathrm{C}$. This increase in temperature is directly proportional to the increase of atmospheric concentration in greenhouse gases, mainly methane and carbon dioxide, for which human emissions are considered the primary cause. The majority of scientists believe that a further increase in greenhouse gas emissions could threaten humanity ${ }^{[4]}$.

Climate changes will have severe effects on the health of humans, domestic animals, and wildlife. Climate change is not only affecting the large organisms, but it also has a detrimental effect on micro-habitat ${ }^{[25]}$. In the lowland forests in Costa Rica, the reptilian and amphibian populations have declined via climate change on the humid leaf litter micro-habitat of the forest floor ${ }^{[5]}$. Fewer sightings of wildlife - bird diversity dropped and Black Bear, wolf, snow Leopards, Markhor, and Himalayan Ibex, no longer seen in northern Pakistan ${ }^{[6]}$.

Greenhouse gases like carbon dioxide absorb heat emitted from the earth. The increase of these gases in the atmosphere leads to warm earth by trapping more and more heat. Human activities like the burning of woods and fossil fuels lead to the formation of gases that contributes to a greenhouse, air pollution, and increasing atmospheric carbon dioxide up to $40 \%$, with more in half the increase occurring since the 1970s. Since 1900 the global temperature has been raised by $0.8^{\circ} \mathrm{C}\left(1.4^{\circ} \mathrm{F}\right)^{[24]}$. Most of the studies showed an increase in temperature is due to an increase in the release of $\mathrm{CO} 2$ and other gases that contribute to the greenhouse. Further increase in these gases will cause further climate change, including a substantial increase in regional climate changes and global average surface temperature. Over many decades, a long time depends only on the amount of greenhouses gases (CO2) emitted as a result of human activities ${ }^{[12]}$.

There is a specific range of environmental conditions for every organism to live. If some abiotic factors such as oxygen concentration shift or precipitation or temperature increase or decrease in such a way that these are outside the range required for a particular specie, then in that habitat, the existence of particular species becomes impossible ${ }^{[13]}$. Variations in global temperatures have wide-ranging effects on environmental conditions and are expected to decline the population of species ranging from tropical corals to Midwestern mammals ${ }^{[14]}$. Many scientists believe that global temperature increases due to human activities like the burning of fossil fuels and woods. While some dispute this claim, arguing that temperature increases are part of the earth's natural climate cycle $^{[15]}$. Some events can eliminate a particular species, such as a massive volcanic eruption, an asteroid strike, or even a rapid loss of large areas of critical and unique habitat because of deforestation. To date, evidence suggests that deforestation is currently and is projected to continue to be the leading indirect and direct cause of reported extirpations ${ }^{[16]}$. For example, because of the ongoing and past deforestation, it is predicted that approximately $21 \%$ of the Southeast Asian forest species will be lost by 2100 ${ }^{[17]}$. The ecosystem and biological community changes precipitated by invasive species represent another leading cause of biodiversity loss ${ }^{[18]}$. Climate change mediated by humans represents a potentially disastrous sleeping giant in terms of future biodiversity losses ${ }^{[19]}$. There are five principal ways through which the species can be affected by climate warming. These are Range shifts, either pole-ward or upward in elevation; alterations of species densities (including altered community composition and structure); Changes in morphology, such as body size; behavioral changes, such as the phenology (seasonal timing of life cycle events) of migration, breeding, and flowering; and Reduction in genetic diversity that leads to inbreeding depression ${ }^{[7]}$.

This study has been conducted in congruence with other research works being conducted. This means that the study highlights the areas which are not entirely addressed by the existing studies. Thus, it serves as an ancillary tool to support the ongoing studies on biodiversity, glaciers, wildlife, and forestry, all directly affected by climate change patterns. 


\section{Materials and Methods}

The details of the study area are described below.

\subsection{Targeted Area and Duration}

The study area that we targeted were the District: Dir Lower, KP, Pakistan. The field study for the case of study was conducted from 10 June-10 November 2018.

\subsection{Methodological and Structure Approach}

Research Design, Research Instrument, and Research Phases and Activities

The present study was collected the required information from primary as well as from secondary sources. Primary field data was collected through documenting observations of local communities. A survey questionnaire was designed to gather primary data for the study. The study process was involved in several steps, including:

\subsection{Secondary Data}

Secondary data on temperature and precipitation were obtained from various sources, the local CBO (Community Based Organization), including WWF (World Wide Fund) Pakistan. Other internet-based research and literature helped in identifying the leading climate change concerns specific to areas.

\subsection{Questionnaire}

Based on information collected on climate change and wildlife, a questionnaire was designed. The questionnaire included information on climate change and its impact on wildlife and wildlife affected by climate change.

\section{Pre-testing}

The approved questionnaire was pre-tested in a village called Hoppy. Based on the interview conducted, minor revisions were made in the questionnaire to concise and incorporate contextual evidence and make the tool more focused (on climate change-related indicators), so that utility and the targeted response were ensured.

\subsection{Field Visit Plan}

The field visit schedule encompassed the following components. Targeted areas and villages were covered by each of the two survey teams sample size. For the survey, the total number of household members (male and female) were interviewed. Each made the date of visits to the two survey teams.

\subsubsection{Data Collection}

Project partners conducted the field of the survey; data were collected from the interviewees. In addition to interview sessions with general community members, local key persons were also interviewed.

\subsubsection{Database Development}

A specific format was designed to feed in the field data collected. The entire information gather was consolidated and stored electronically.

\subsubsection{Data Analysis}

The data analysis procedure involved preliminary coding and sorting of data, mostly through data reduction (writeups of field notes) and data reconstruction (development of categories, findings, conclusions, connections to existing literature, integration of concepts). The data was then presented in a narrative report of findings with descriptive and interpretative details.

\section{Results}

\subsection{The Rate of Monthly Rain}

As a global temperature change, the rain rate in DIR Lower changes, as shown in the graph No.1 (Pakistan Meteorological Department). On Jan and Feb 2010-2018, there is a sharp increase up to $250 \mathrm{~mm}$ except found in 2010 and 2018. And then a sharp decrease of $50 \mathrm{~mm}$ in April and May in 2010, 2011, 2013, 2014, 2015, 2016, 2017, and 2018, respectively. In June and August, a sharp increase of 100mm-200mm was found 2010- 2015 except 2011. In September and October, the rain rate was found mostly below $50 \mathrm{~mm}$ expect 2014. There was a sharp increase up to above $150 \mathrm{~mm}$. In November and December, there was a mostly linear rate below $50 \mathrm{~mm}$. The graph shows two regular sharp increases in January and July and a regular sharp decrease in May and September, while mostly the increase and decrease in the raining rate is not regular, especially and March, April, June, and October, as shown in Table 1 and Figure 1.

Table 1. Monthly total rain rate $(\mathrm{mm})$ of the past eight years $(2010-2018)$

\begin{tabular}{|c|c|c|c|c|c|c|c|c|c|c|c|c|}
\hline YEAR & JAN & FEB & MAR & APR & MAY & JUN & JUL & AUG & SEP & OCT & NOV & DEC \\
\hline $\mathbf{2 0 1 0}$ & 62 & 220 & 44 & 31 & 40.5 & 28 & 424 & 153 & 56.6 & 0 & 0 & 0 \\
\hline $\mathbf{2 0 1 1}$ & 25 & 258 & 88 & 72 & 21 & 40 & 54 & 61 & 33 & 66 & 15 & 0 \\
\hline $\mathbf{2 0 1 2}$ & 82 & 94 & 35 & 89 & 39 & 3 & 74 & 150 & 107 & 14 & 20 & 69 \\
\hline $\mathbf{2 0 1 3}$ & 6 & 247 & 103 & 97 & 22 & 98 & 97 & 205 & 55.2 & 30 & 52 & 0 \\
\hline $\mathbf{2 0 1 4}$ & 0 & 148 & 175 & 158 & 50 & 50 & 36.2 & 50 & 68 & 163 & 23 & 0 \\
\hline $\mathbf{2 0 1 5}$ & 117.0 & 241.0 & 252.0 & 183.0 & 102.0 & 98.0 & 175.0 & 146.0 & 35.0 & 103.0 & 182.0 & 63.0 \\
\hline $\mathbf{2 0 1 6}$ & 114.5 & 101.0 & 323.0 & 236.0 & 88.0 & 73.0 & 114.0 & 176.0 & 43.0 & 8.0 & 9.0 & 29.0 \\
\hline $\mathbf{2 0 1 7}$ & 290.0 & 190.0 & 91.0 & 114.0 & 65.0 & 86.0 & 62.0 & 106.0 & 97.0 & 40.0 & 26.0 & 44.0 \\
\hline $\mathbf{2 0 1 8}$ & 0.0 & 73.0 & 77.0 & 85.0 & 71.0 & 31.0 & 110.0 & 82.0 & 23.0 & 35.0 & 35.0 & 21.0 \\
\hline
\end{tabular}




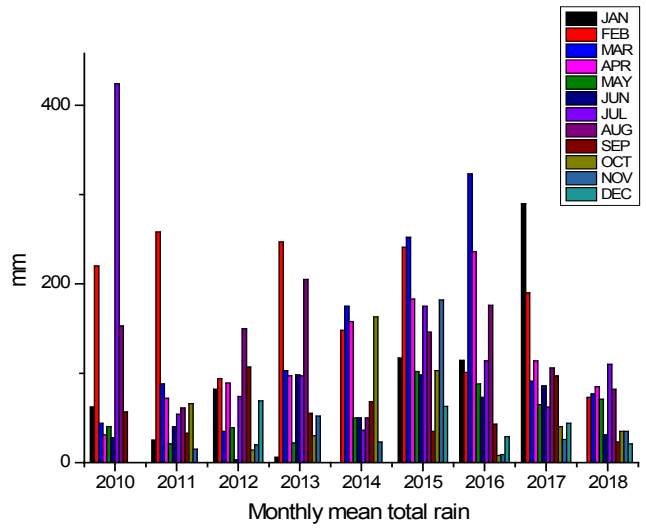

Figure 1. Monthly total rain rate $(\mathrm{mm})$ of past eight years (2010-2018)

\subsection{Monthly Mean Minimum Temperature}

The data were collected from the Pakistan Meteorological Department, which shows variation clearly in minimum temperature as the year past. While 2010 seems warm as compared to the next three years $(2011,2012$, and 2013), while the next two years (2014-2018) is warm more than the past two years (2012 and 2013). Thus a little increase is found overall in the last five years. The average minimum temperature in the last five years was $13.0^{\circ} \mathrm{C}$. The lowest temperature was found in $2011-1.3^{\circ} \mathrm{C}$ followed by -1.5 in December 2010, as shown in Table 2 and Figure 2.

Table 2. Monthly mean Minimum temperature of the past eight years (2010-2018)

\begin{tabular}{|c|c|c|c|c|c|c|c|c|c|c|c|c|}
\hline YEAR & JAN & FEB & MAR & APR & MAY & JUN & JUL & AUG & SEP & OCT & NOV & DEC \\
\hline $\mathbf{2 0 1 0}$ & 1.8 & 5.3 & 12.5 & 16.7 & 20.5 & 22.8 & 24.4 & 23.7 & 19 & 14.7 & 5.4 & -1.5 \\
\hline $\mathbf{2 0 1 1}$ & -1.7 & 3.3 & 9 & 12.4 & 19.7 & 23.4 & 23 & 22.8 & 18.7 & 12.4 & 7.5 & -1.3 \\
\hline $\mathbf{2 0 1 2}$ & 0 & 2.1 & 8.5 & 13.6 & 16.5 & 21.9 & 24 & 22.3 & 17.6 & 11.6 & 6.3 & 3.6 \\
\hline $\mathbf{2 0 1 3}$ & 1.2 & 3.8 & 8.5 & 13.9 & 19.7 & 24.1 & 23.7 & 22.8 & 19.9 & 15.6 & 5.6 & 2.3 \\
\hline $\mathbf{2 0 1 4}$ & 0.8 & 4.7 & 8.3 & 13.6 & 17.7 & 23 & 24.6 & 22.6 & 20.1 & 14.7 & 6 & 0.5 \\
\hline $\mathbf{2 0 1 5}$ & 1.5 & 5.3 & 9.1 & 14.1 & 19.3 & 22.5 & 24.1 & 22.8 & 0 & 14.4 & 7.6 & 2.3 \\
\hline $\mathbf{2 0 1 6}$ & -2.6 & -1.9 & 3.0 & 6.1 & 11.0 & 14.5 & 17.3 & 14.4 & 12.3 & 6.4 & 2.1 & -0.9 \\
\hline $\mathbf{2 0 1 7}$ & -2.6 & -1.2 & 2.6 & 6.8 & 10.7 & 14.2 & 18.2 & 15.7 & 11.2 & 5.7 & 0.9 & -2.2 \\
\hline $\mathbf{2 0 1 8}$ & 0.2 & 4.4 & 10.9 & 15.1 & 19.9 & 24.0 & 24.3 & 24.0 & 20.0 & 13.1 & 7.0 & 0.3 \\
\hline
\end{tabular}

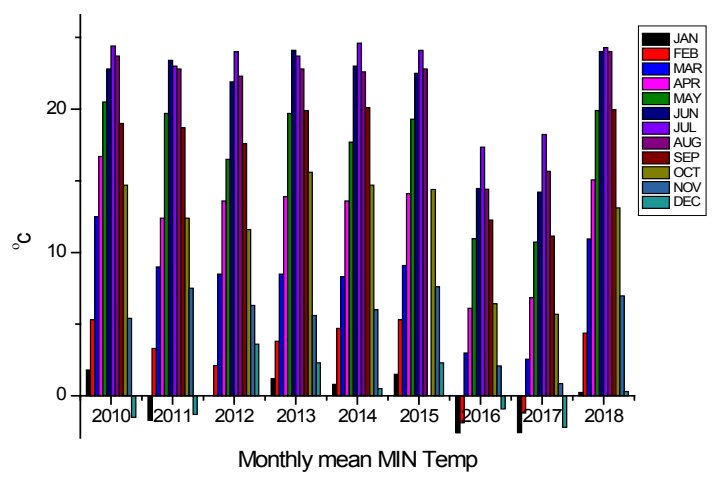

Figure 2. Monthly mean Minimum temperature of the past eight years (2010-2018)

\subsection{Monthly Mean Maximum Temperature}

The data were collected from the Pakistan Meteorological Department, which shows variation clearly in maximum temperature as the year past. 2010 was the warmest year in the past five years. The next year 2011, was also warmer while the little variation was found in 2012 and 2103, mostly in January and February, while 2014 is the second warmest year in the last five years followed by 2015 to 2018. The overall values show a little increase in the last five years. The highest temperature was found in July in $2014,39.6{ }^{\circ} \mathrm{C}$, followed by $39.0^{\circ} \mathrm{C}$ in June 2011 and July 2012, as shown in Table 3 and Figure 3.

Table 3. Monthly mean maximum temperature of the past eight years (2010-2018)

\begin{tabular}{|c|c|c|c|c|c|c|c|c|c|c|c|c|}
\hline YEAR & JAN & FEB & MAR & APR & MAY & JUN & JUL & AUG & SEP & OCT & NOV & DEC \\
\hline $\mathbf{2 0 1 0}$ & 18.7 & 15.5 & 27.2 & 31.7 & 34.5 & 37.3 & 36.4 & 33.1 & 32.9 & 30.3 & 23.6 & 16.5 \\
\hline $\mathbf{2 0 1 1}$ & 16.3 & 14.1 & 23.9 & 27.9 & 37.7 & 39 & 36.3 & 35.6 & 33.4 & 27.7 & 22.1 & 16.9 \\
\hline $\mathbf{2 0 1 2}$ & 13.3 & 14.1 & 22 & 28 & 33.4 & 38.9 & 39 & 35.9 & 32.8 & 29.4 & 22.7 & 15.4 \\
\hline $\mathbf{2 0 1 3}$ & 15.5 & 16.3 & 23.2 & 28.6 & 36.3 & 38.4 & 36.4 & 34.9 & 33.7 & 30 & 20.9 & 17.7 \\
\hline $\mathbf{2 0 1 4}$ & 17.2 & 16.8 & 19.5 & 27.2 & 32.8 & 39.6 & 38.1 & 36.8 & 34.8 & 28.3 & 21.4 & 17.7 \\
\hline $\mathbf{2 0 1 5}$ & 15.6 & 17.6 & 21.4 & 28.7 & 34.2 & 36.9 & 35.7 & 35 & 0 & 29.4 & 20 & 16.4 \\
\hline $\mathbf{2 0 1 6}$ & 14.6 & 17.7 & 18.4 & 22.7 & 30.4 & 33.3 & 32.9 & 31.9 & 31.2 & 28.5 & 22.8 & 20.1 \\
\hline $\mathbf{2 0 1 7}$ & 10.1 & 15.4 & 18.7 & 25.3 & 30.5 & 32.5 & 32.4 & 32.1 & 30.7 & 28.0 & 21.7 & 17.4 \\
\hline $\mathbf{2 0 1 8}$ & 17.7 & 19.2 & 25.6 & 30.2 & 33.3 & 39.8 & 36.8 & 35.9 & 35.2 & 29.3 & 22.1 & 17.3 \\
\hline
\end{tabular}

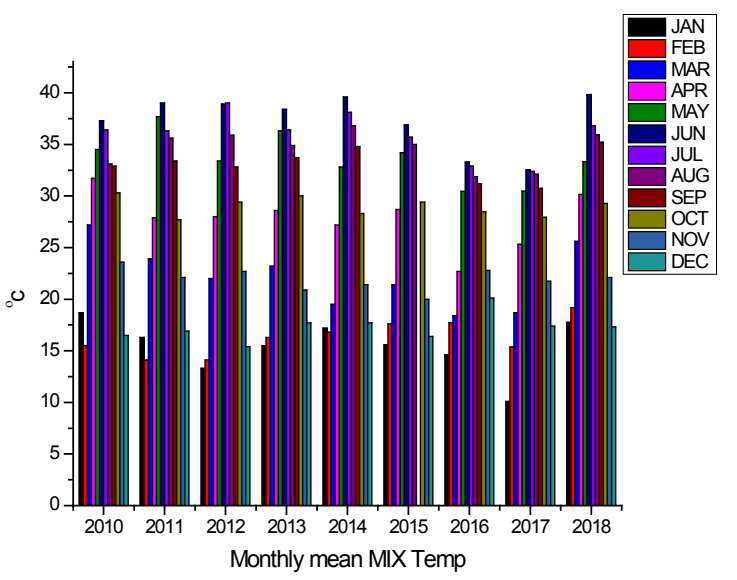

Figure 3. Monthly mean maximum temperature of the past eight years (2010-2018)

\section{Discussion}

Results show a notable change found in Temperature, rainfall rate, snowfall, drought, deforestation, and indirect effect on climate. Also, the effect of climatic change has been observed, and the most notable effect is on wildlife and human health

\subsection{Changes in Climate}

We observed that many factors harm climate through 
results analysis, and these factors are dominating day by day. Most people observe climate change, and human activities with natural phenomena enhance these factors' effects. As our result showed that temperature somewhat changes and high variation is found in the past eight years, many other surveys like The study of Farooqi, Khan ${ }^{[8]}$ showed that Analysis of the past depicts that our climate is changing. The main factors involved are greenhouse gas emissions, natural phenomena, etc. and their effect on water resources, and subsequently affect food supply, health, industry, transportation, and ecosystem sustainability. Our study also mentions that the major causes of climatic change are deforestation; mostly, $100 \%$ responders were agreed. It is a significant factor contributing to climate change in this area, which is in line with the previous study of Malmsheimer Bowyer ${ }^{[9]}$. Our study showed that rapid deforestation also has a significant contribution to a decrease in rainfall and an increase in greenhouse gases and subsequently causes climatic change, the same wise the previous study of da Silva Dias ${ }^{[10]}$ showed the same effect. According to the current study, the incidence of diseases has a prominent effect on the wildlife growth rate caused by polluted water caused by deforestation, flooding, industrialization, urbanization, sewage, etc. The same results were obtained by the study of Malmsheimer, Bowyer ${ }^{[9]}$.

\subsection{Effect of Climatic Change on Wild Life}

As the results showed, dramatic changes occur in the climate, which leads to severe problems such as Wildlife extinction, health problems, a decrease in crop production, a decrease in drink water, and many more. The climatic changes cause the rapid habitat loss of wildlife and pollution, which forces them to displace or eliminate or extinct. When an environment altered abruptly or systematically at a rate above the average background change, or beyond the capacity of adaptation via natural selection, specialist species with narrow ecological niches often bear the brunt of progressively unfavorable conditions such the loss of habitat and degradation (studied by Sodhi, Lee) ${ }^{[7]}$.

A study of the US Department of the interior, fishes, and wildlife Manchester showed that One-third of 165 species of wetland breeding birds show medium or high vulnerability to climate change, and black ducks have been identified as the most susceptible to sea-level rise associated with a warming climate ${ }^{[22] .}$

Our study mention all the threats toward wildlife, primarily through climate change while the same case was Studied by Kronstadt ${ }^{[1]]}$, showed that the moderate climatic change puts some of this biodiversity at considerable risk, the rise in average global temperature will influ- ence the length and severity of season and the frequency and severity of floods and drought, increasing the prevalence of fire and predisposition to pests and pathogens with the expected impact on forest habitats and species. About one quarter of vascular plants and higher animals on the globe are estimated to be at increasingly high risk of extinction as temperature rise by 2-3C above pre-industrial levels. Even more modest losses in biodiversity would likely affect the ecosystem services ${ }^{[23]}$.

As the global average temperature continues to rise, it is essential to develop strategies to conserve species and habitats that are unable to adapt, measure to reduce the impact of other human pressure, which still exceed those of climate change in most case are also likely to help reduce the overall vulnerability of forest ecosystem to climate change, more radical measure for adopting forests and wildlife to climate change include modifying or newly creating habitats, trans-locating whole animal and plant communities and moving boundaries of the protected area.

\section{Conclusion}

It is concluded from the study that people are severely noticing the climatic change and their leading causes were greenhouse gases and deforestation. So, it is vital to decrease those activities whose is responsible for greenhouses gases and also to decrease deforestation and promote forestation locally as well as globally. The study also concluded that industrialization and vehicles are responsible for the greenhouse gases that cause global warming in consequences their effect on the environment are, decrease in rain rate, increase in diseases, migration of birds, decrease in drink water for human and wildlife. As the climatic changes increase, wildlife's life becomes in danger and leads to migration or extinction. To control the climatic change and wildlife extinction, we need a forest conservation policy, wildlife conservation, prevent hunting, industrial pollution control, vehicle pollution control, increase in plantation, awareness of the policy for the control of climatic change, etc.

\section{References}

[1] Change, I.C. IPCC third assessment report. World Meteorological Organisation and UNEP http://www. ipcc, 2001.

[2] Joos, F., et al. Global warming feedbacks on terrestrial carbon uptake under the Intergovernmental Panel on Climate Change (IPCC) emission scenarios. Global Biogeochemical Cycles, 2001, 15(4): 891-907.

[3] McMichael AJ, Powles JW, Butler CD, Uauy R. 
Food, livestock production, energy, climate change, and health. The lancet, 2007, 370(9594): 1253-63.

[4] Rockström, J., et al. A safe operating space for humanity. nature, 2009, 461(7263): 472-475.

[5] Hasnat GT, Kabir MA, Hossain MA. Major environmental issues and problems of South Asia, Particularly Bangladesh. Handbook of environmental materials management. 2018: 1-40.

[6] Bazargan, A., A multidisciplinary introduction to desalination. Stylus Publishing, LLC, 2018.

[7] Sodhi, N.S., et al. A meta $\square$ analysis of the impact of anthropogenic forest disturbance on Southeast Asia's biotas. Biotropica, 2009, 41(1): 103-109.

[8] Farooqi, A.B., A.H. Khan, H. Mir. Climate change perspective in Pakistan. Pakistan Journal of Meteorology, 2005, 2(3).

[9] Malmsheimer, R.W., et al. Managing forests because carbon matters: integrating energy, products, and land management policy. Journal of Forestry. 2011, 109(7S): S7-S50.

[10] da Silva Dias, M.A.F. Forest and Rainfall Interactions in the Amazon Basin. 2008.

[11] Kronstadt, K.A. Flooding in Pakistan: Overview and issues for congress. 2010: DIANE Publishing.

[12] Solomon S, Plattner GK, Knutti R, Friedlingstein P. Irreversible climate change due to carbon dioxide emissions. Proceedings of the national academy of sciences. 2009, 106(6): 1704-9.

[13] Sodhi NS, Brook BW, Bradshaw CJA. Causes and consequences of species extinctions. In: Levin SA, editor. The Princeton Guide to Ecology. Princeton, NJ:Princeton University Press: 2009: 514-20.

[14] Handmer J, Honda Y, Kundzewicz ZW, Arnell N, Benito G, Hatfield J, Mohamed IF, Peduzzi P, Wu S, Sherstyukov B, Takahashi K. Changes in impacts of climate extremes: human systems and ecosystems. InManaging the risks of extreme events and disasters to advance climate change adaptation special report of the intergovernmental panel on climate change. Intergovernmental Panel on Climate Change, 2012: 231-290.

[15] McComas K, Shanahan J. Telling stories about glob- al climate change: Measuring the impact of narratives on issue cycles. Communication research, 1999, 26(1): 30-57.

[16] Posner EA, Weisbach D. Climate change justice. Princeton University Press, 2010.

[17] Sodhi NS, Posa MR, Lee TM, Bickford D, Koh LP, Brook BW. The state and conservation of Southeast Asian biodiversity. Biodiversity and Conservation, 2010, 19(2): 317-28.

[18] Pyšek P, Richardson DM. Invasive species, environmental change and management, and health. Annual review of environment and resources, 2010, 35.

[19] Sodhi NS, Brook BW, Bradshaw CJ. Causes and consequences of species extinctions. The Princeton guide to ecology, 2009, 1(1): 514-20.

[20] WWF Pakistan. Climate Change in the Northern Areas Pakistan: Impacts on glaciers, ecology and livelihoods. Pakistan, 2008.

[21] National Academy of Sciences (NAS) 2001. Climate Change Science: An Analysis of Some Key Questions. National Academies Press. 2001: 42.

[22] Change, A.D.G. Climate change science: An analysis of some key questions. National Academies Press, 2001.

[23] Whitfield, S.M., et al. Amphibian and reptile declines over 35 years at La Selva, Costa Rica. Proceedings of the National Academy of Sciences, 2007. 104(20): 8352-8356.

[24] Cusack C. Fish, Justice, and Society. Brill, 2018.

[25] Leadley P. Biodiversity scenarios: projections of 21 st century change in biodiversity, and associated ecosystem services: a technical report for the global biodiversity outlook 3. UNEP/Earthprint, 2010.

[26] Goeppert A, Czaun M, Prakash GS, Olah GA. Air as the renewable carbon source of the future: an overview of CO 2 capture from the atmosphere. Energy \& Environmental Science. 2012, 5(7): 7833-53.

[27] Potts SG, Biesmeijer JC, Kremen C, Neumann P, Schweiger O, Kunin WE. Global pollinator declines: trends, impacts and drivers. Trends in ecology \& evolution. 2010, 25(6): 345-53. 